\title{
RADEC (Reading, Answering, Demonstrating, Explaining, and Creating) in LMS to Teach Tennis without Field Practicing
}

\author{
Aam Ali Rahman*, Ayi Suherman, Dewi Susilawati, Gilang Pratama Putra \\ Elementary Physical Education Teacher Program, Universitas Pendidikan Indonesia, Indonesia
}

Received July 24, 2020; Revised August 27, 2020; Accepted September 29, 2020

\section{Cite This Paper in the following Citation Styles}

(a): [1] Aam Ali Rahman, Ayi Suherman, Dewi Susilawati, Gilang Pratama Putra , "RADEC (Reading, Answering, Demonstrating, Explaining and Creating) in LMS to Teach Tennis without Field Practicing," Universal Journal of Educational Research, Vol. 8, No. 11, pp. 5433 - 5442, 2020. DOI: 10.13189/ujer.2020.081146.

(b): Aam Ali Rahman, Ayi Suherman, Dewi Susilawati, Gilang Pratama Putra (2020). RADEC (Reading, Answering, Demonstrating, Explaining, and Creating) in LMS to Teach Tennis without Field Practicing. Universal Journal of Educational Research, 8(11), 5433 - 5442. DOI: 10.13189/ujer.2020.081146.

Copyright $\bigcirc 2020$ by authors, all rights reserved. Authors agree that this article remains permanently open access under the terms of the Creative Commons Attribution License 4.0 International License

\begin{abstract}
The learning obstacles stimulate learning practitioners and researchers to find and to analyze the most proper and fitter learning methodology and approach of the most effective learning. One of the education obstacles currently happens is the Covid-19 pandemic that prevents direct interaction between lecturers and students. As the direct interaction between lecturers and students was mostly used as the learning approach, this pandemic makes inevitable learning processes inevitable. However, RADEC (Reading, Answering, Demonstrating, Explaining, Creating) in LMS allows lecturers to teach Tennis without field practicing. To analyze the effectiveness, 63 participants were employed and grouped into control (30 participants) and the experimental group (33 participants). The independent sample t-test for both cognitive and practical achievements was used to analyze the data. The significant results of sig. (2-tailed) are 0.103 for cognitive, 0.547 for practical, and 0.541 for a total with $\alpha=0.05$. All of the results are higher than $\alpha=0.05$. It means that all null-hypothesis is accepted. It can be concluded that there is no significant difference between conventional tennis teaching and RADEC in LMS. In other words, RADEC in LMS can be one of the alternative methods of teaching Tennis during this pandemic that prevents direct teaching and learning process. In general, this research serves other teaching practical innovations, especially for teaching Tennis using LMS without a direct learning process.
\end{abstract}

Keywords Teaching Tennis, LMS, Teaching during Pandemic, Education

\section{Introduction}

Choosing the proper learning media and applying it to the learning strategy is not easily manageable[1]. It requires some comprehended analysis of the material, the learning aids, and the students' characteristics. Further, the learning media and learning aids cannot be separated into successful learning. It affects the learning outcome [2-4]. Thus, choosing the best learning media is one of the keys to a successful learning outcome.

That circumstance of learning is applied to almost different types of knowledge, other teaching methods, and learners' characters. Because of that, a proper learning media is inevitably essential. It should reduce the learning obstacles faced by learners and teachers. However, the current pandemic issue is giving more hindrances to learning. It becomes another factor affecting learning outcomes. The UN Educational, Scientific, and Cultural Organization reports that 138 nations have their schools closed. It affects the education of $80 \%$ of students across the globe [5]. Consequently, teachers, trainers, lecturers, or educators must find the best way to apply their teaching 
method without having the learners in the same classroom.

While typical classroom learning is not an option for educators, they who teach practical, such as physical education teachers, face one step more burden. The learning achievements for practical require students to do things, move, and act according to the lesson. For sure, the typical learning media system (LMS) is not enough. Modification to LMS is inevitable to achieve sufficient learning.

One of the many subjects offered in university for those who take sports as their major is Tennis. This sport can increase aerobic capacities, lower the resting rate of heart and blood pressure, enhance metabolic function, increase bone density, lower body fat, improve muscle tone, strength, flexibility, and increase reaction time [6]. It is a recreational sport that may heat up with close friends and family.

However, in Indonesia, Tennis is not as popular as football. Not all citizens are familiar with this type of sport. Even most of them do not have experience holding a tennis racket or finding a tennis court.

Only some university students who take sports as their major know how to play and have experienced Tennis. In their previous education (elementary or secondary schools), the physical education curriculum does not include Tennis. As a consequence, Tennis is a new thing for them. This condition becomes another obstacle for lecturers.

From all previous obstacles mentioned, successful learning outcomes is depended on lecturers' creativity to create an appropriate teaching aid to teach Tennis during the COVID-19 pandemic. Some experts have researched teaching Tennis. Reference [7] offers a game-based teaching approach to teach Tennis. They used discovery and problem-solving. Another research has been done by Pill and Hewitt [8]. It demonstrates how novice tennis players enhance their ability through a game. Reference [9] also studied using the inquiry teaching method to teach Tennis for college students. It mainly focuses on cultivating students' creative ability to promote the development of Tennis. Further, innovation in teaching tennis has also been done by Mowling et al.[10]. They used the sound ball to teach blind or visually impaired students to learn Tennis.

However, almost all research related to teaching tennis requires lecturers or tutors to attend to the tennis court. The direct interaction is necessary to apply the method offered. Since this COVID-19 pandemic prevents direct interaction with students more innovative, learning media that suits the condition is required. The media that allows students to learn Tennis interactively without doing direct interaction with tutors and other players. Thus, the Learning Management System (LMS) is a core of media implementation for teaching aids.

A combination method of learning by Reading, Answering, Demonstrating, Explaining, and Creating (RADEC) applied in the Learning Management System (LMS) may become a solution to teach Tennis during this
COVID-19 pandemic. Reading and Answering are the most common method of teaching. These methods are widely applied to almost all teaching methodologies. It can form a verbal content simulation using neural and bodily systems of perception, action, and emotion [11].

Followed by demonstrating, the prior knowledge they get from Reading and Answering is applied. It is a visualization of a text that reveals knowledge [12]. In this step, learners demonstrate what they know about the material, then continued to Explaining where lecturers explain and discuss the learners' demonstration. In the end, after learners comprehend the complete lessons, they require to find out a new innovative movement different from the common one. All of those steps: Reading, Answering, Demonstrating, Explaining, and Creating (RADEC) are applied to selected Learning Management System (LMS) to teach Tennis.

In sum, this research investigates how RADEC in LMS affects learning goals of teaching Tennis for university students without direct practical activity. Afterward, cognitive knowledge, practice, and total scores were analyzed.

\section{Methods}

This research was conducted through two main phases: Preparation phase and Application. The preparation phase was used to find out the learners' characteristics related to their knowledge of Tennis. In this phase also, the development of RADEC in LMS was done. The next stage is the implementation phase. In this phase, the developed learning media (RADEC in LMS) was applied to be tested to participants.

\section{Research Design}

Quantitative analysis using a quasi-experimental design was used to test the hypothesis. This research involved two groups: control and experiment. The control group was given a typical teaching tennis procedure, while the experimental group learned Tennis using RADEC in LMS. A quasi-experiment was chosen because this research participants were not randomly selected, and ideal control for every participant could not be done [13-15].

As it was mentioned previously, the participants of this research were taken purposively. Sixty-three university students who take sports education as their major participated in this research. The participants were grouped: 33 participants were in the experimental group, and 30 others were in the control group. In specific, the control group got direct lecturing with discovery learning methodology. They also got chances to do direct practicing in the field for six basic tennis movements: serve, forehand groundstroke, backhand groundstroke, forehand volley, backhand volley, and overhead smash. Simply, participants were given lecturers related to six basic tennis movements. 
Further, the lecturer gave the example of the movement, and the last, participants did field practicing and innovating their movements.

Meanwhile, in the experimental group, participants were given all the lecturing through LMS for those six basic movements. Lecturers asked participants to search for information related to the material before explaining through video conferences. After explaining, the participants were doing self-practicing and reporting the progress in the LMS. The movements were performed in the video taken from many sources on YouTube.

\section{Research Procedure}

After the groups were formed, both groups were tested to check the homogeneity of variances. The tests were taken from the university curriculum goal for Tennis. Two different tests (cognitive and practical) were given to check Tennis's initial ability and knowledge. The cognitive test was taken from the part of the curriculum related to six basic tennis movements. Meanwhile, the practical test is limited to the partial movements recorded. The participant in the experiment group was asked to record the six basic tennis movements. This limitation may cause a lack of control for participants' physical fitness and skill-building and focus only on the test result.
Further, the tests were given as a post-test after both groups were given different treatments. The test items (cognitive and practical) were the same test as the pre-test. This post-test was used to compare the effectiveness of RADEC in LMS to typical tennis teaching. Since the parametric $t$-test calculation was employed, Normality and homogeneity of variances were tested to ensure the prerequisite data was fulfilled.

\section{Result and Discussion}

This research used independent samples t-test to associate both the control and experimental groups. Thus, pre and post-tests were given to both groups. The pre-test was used to calculate prerequisite analysis for the parametric test. Normality and homogeneity of variance were analyzed for the cognitive knowledge, the practical, and the pre-test's total result.

\section{The Cognitive Pre-Test Result for The Control and Experimental groups}

The pre-test in the form of 40 multiple questions, and five structured questions were given to both groups. The scores were used to analyze Normality and homogeneity of variance for both groups. The result is presented as follows.

Table 1. The Cognitive Pre-test Descriptive Result

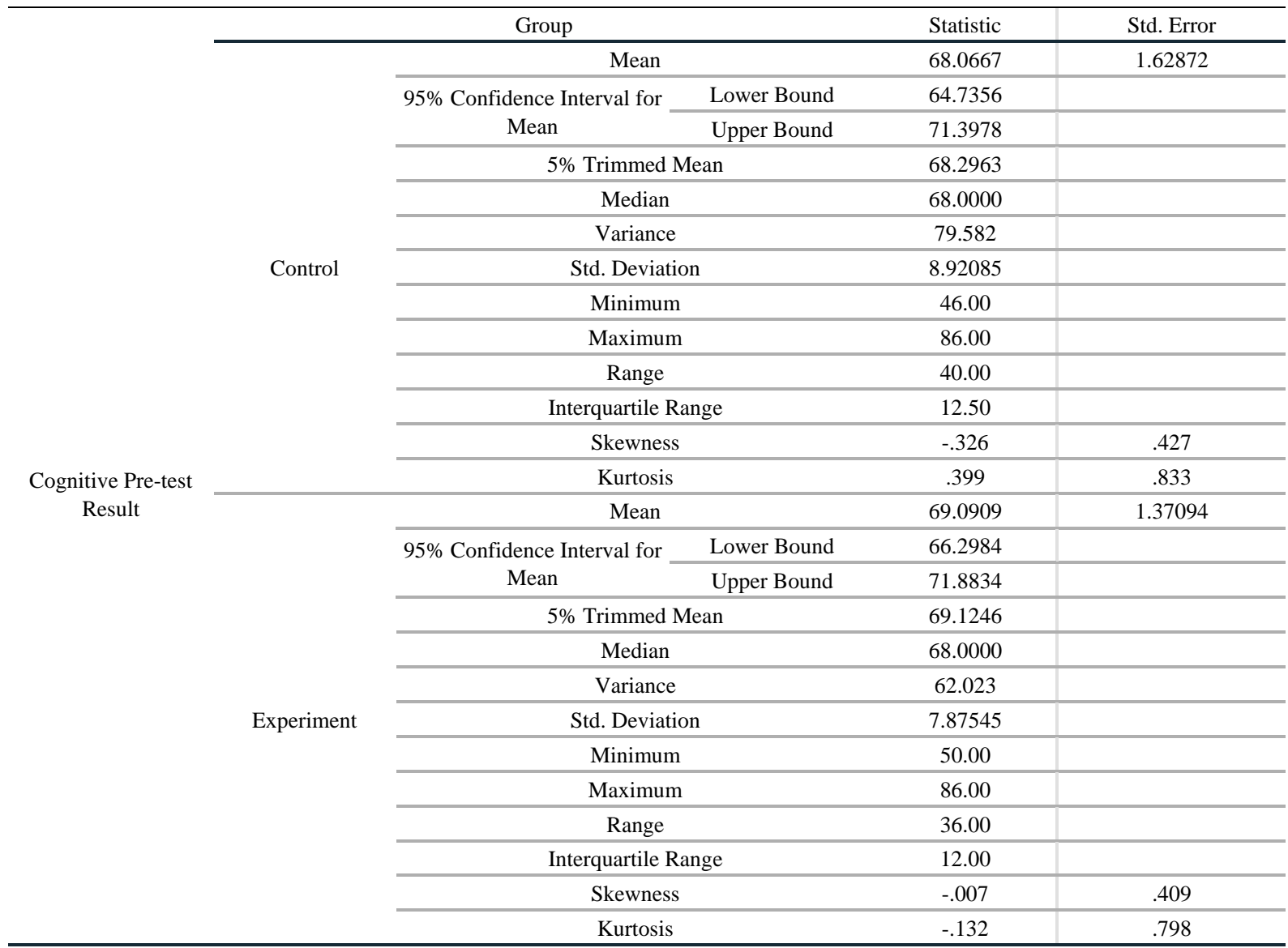


Specifically, the Normality and homogeneity of the variance test result for cognitive scores of both control and experimental groups are presented in Table 2 and Table 3.

Using Kolmogorov-Smirnov and Shapiro-Wilk, the normality test for both control and experimental groups were analyzed. As a result, the control group's significant result is 0.794 , and for the experimental group is 0.622 . Both significance results are higher than 0.05 , so it can be stated that both groups are normally distributed based on the cognitive pre-test score.
Meanwhile, to test the homogeneity of variance Levene Statistic was employed. The data from table 2 shows that the significant result is 0.745 . This significance result is higher than 0.05 . Thus, based on the Levene Statistic result, both groups are homogeny. The analysis presented in table 2 and table 3 shows that both control and experimental groups are normally distributed and considered homogeny. So, independent sample t-test analysis can be conducted for cognitive scores.

Table 2. Test of Normality Data for Cognitive Pre-test Score

\begin{tabular}{lcccccccc}
\hline & \multirow{2}{*}{ Group } & \multicolumn{3}{c}{ Kolmogorov-Smirnov $^{\mathrm{a}}$} & \multicolumn{4}{c}{ Shapiro-Wilk } \\
\cline { 3 - 9 } & & Statistic & $\mathrm{df}$ & Sig. & Statistic & df & Sig. \\
\hline \multirow{2}{*}{ Cognitive Pre-test Result } & Control & .091 & 30 & $.200^{*}$ & .979 & 30 & .794 \\
\cline { 2 - 9 } & Experiment & .131 & 33 & .164 & .975 & 33 & .622 \\
\hline
\end{tabular}

*. This is a lower bound of the true significance.

a. Lilliefors Significance Correction

Table 3. Test of Homogeneity of Variance for Cognitive Pre-test Scores

\begin{tabular}{cccc}
\hline & Cognitive Pre-test Result & & \\
\hline Levene Statistic & $\mathrm{df} 1$ & $\mathrm{df2}$ & Sig. \\
\hline .106 & 1 & 61 & .745 \\
\hline
\end{tabular}

Table 4. The Practical Pre-test Descriptive Result

\begin{tabular}{|c|c|c|c|c|c|}
\hline & & Group & & Statistic & Std. Error \\
\hline & & Mean & & 62.6667 & 1.42662 \\
\hline & & 95\% Confidence Interval for & Lower Bound & 59.7489 & \\
\hline & & Mean & Upper Bound & 65.5844 & \\
\hline & & 5\% Trimmed & & 62.7407 & \\
\hline & & Median & & 62.0000 & \\
\hline & & Varianc & & 61.057 & \\
\hline & Control & Std. Devia & & 7.81393 & \\
\hline & & Minimur & & 44.00 & \\
\hline & & Maximu & & 80.00 & \\
\hline & & Range & & 36.00 & \\
\hline & & Interquartile & & 9.00 & \\
\hline & & Skewnes & & -.094 & .427 \\
\hline Practical Pre-tect Recult. & & Kurtosi & & .544 & .833 \\
\hline Practical Pre-test Kesuit & & Mean & & 66.6061 & 1.24159 \\
\hline & & 95\% Confidence Interval for & Lower Bound & 64.0770 & \\
\hline & & Mean & Upper Bound & 69.1351 & \\
\hline & & 5\% Trimmed & & 66.7205 & \\
\hline & & Median & & 66.0000 & \\
\hline & & Varianc & & 50.871 & \\
\hline & Experiment & Std. Devia & & 7.13241 & \\
\hline & & Minimu & & 48.00 & \\
\hline & & Maximu & & 80.00 & \\
\hline & & Range & & 32.00 & \\
\hline & & Interquartile & & 12.00 & \\
\hline & & Skewnes & & -.185 & .409 \\
\hline & & Kurtosi & & -.084 & .798 \\
\hline
\end{tabular}




\section{The Practical Pre-Test Result for The Control and Experimental groups}

Not only the cognitive score but practical tennis scores were also taken as assessment factors. The practical test was adapted based on curriculum objectives for the Tennis subject. It covered serve, forehand groundstroke, backhand groundstroke, forehand volley, backhand volley, and overhead smash. The analysis description is presented in percentage in Table 4.

The result of Kolmogorov-Smirnov and Shapiro-Wilk shows that the significant result for the control and experimental groups is 0.657 and 0.301 . Both results are higher than 0.05 , so it can be stated that both groups are normally distributed. Meanwhile, the result of the homogeneity of variances is presented in Table 6 .

From Table 6, it can be seen that the significance level result is 0.904 . It is higher than 0.05 . So, it can be said that both groups are homogeny based on practical pre-test scores. As well as cognitive scores analysis, both groups' practical ability also fulfills the independent sample $t$-test prerequisites. Both groups have normal distribution data, and their variances are homogeny.

Table 5. Test of Normality Data for Practical Pre-test Score

\begin{tabular}{lcccccccc}
\hline & \multirow{2}{*}{ Group } & \multicolumn{3}{c}{ Kolmogorov-Smirnov $^{\mathrm{a}}$} & \multicolumn{4}{c}{ Shapiro-Wilk } \\
\cline { 3 - 9 } & & Statistic & $\mathrm{df}$ & Sig. & Statistic & $\mathrm{df}$ & Sig. \\
\hline \multirow{2}{*}{ Practical Pre-test Result } & Control & .133 & 30 & .185 & .974 & 30 & .657 \\
\cline { 2 - 10 } & Experiment & .127 & 33 & .190 & .962 & 33 & .301 \\
\hline
\end{tabular}

a. Lilliefors Significance Correction

Table 6. Test of Homogeneity of Variance for Practical Pre-test Scores

\begin{tabular}{cccc}
\hline & Practical Pre-test Result & & \\
\hline Levene Statistic & df1 & df2 & Sig. \\
\hline .015 & 1 & 61 & .904 \\
\hline
\end{tabular}

Table 7. The Total Pre-test Descriptive Result

\begin{tabular}{|c|c|c|c|c|c|}
\hline & & Group & & Statistic & Std. Error \\
\hline & & Mean & & 65.3667 & 1.44277 \\
\hline & & 95\% Confidence Interval for & Lower Bound & 62.4159 & \\
\hline & & Mean & Upper Bound & 68.3175 & \\
\hline & & 5\% Trimmed & & 65.6111 & \\
\hline & & Median & & 64.0000 & \\
\hline & & Varianc & & 62.447 & \\
\hline & Control & Std. Devia & & 7.90235 & \\
\hline & & Minimuı & & 47.00 & \\
\hline & & Maximu & & 79.00 & \\
\hline & & Range & & 32.00 & \\
\hline & & Interquartile & & 11.00 & \\
\hline & & Skewnes & & -.369 & .427 \\
\hline Total Dro toct Docult & & Kurtosi & & .034 & .833 \\
\hline Iolda Pie-test resula & & Mean & & 67.8485 & 1.28962 \\
\hline & & 95\% Confidence Interval for & Lower Bound & 65.2216 & \\
\hline & & Mean & Upper Bound & 70.4753 & \\
\hline & & 5\% Trimmed & & 67.9226 & \\
\hline & & Median & & 66.0000 & \\
\hline & & Varianc & & 54.883 & \\
\hline & Experiment & Std. Devia & & 7.40828 & \\
\hline & & Minimu & & 49.00 & \\
\hline & & Maximu & & 83.00 & \\
\hline & & Range & & 34.00 & \\
\hline & & Interquartile & & 13.00 & \\
\hline & & Skewnes & & -.098 & .409 \\
\hline & & Kurtosi & & -.055 & .798 \\
\hline
\end{tabular}




\section{The Total Pre-Test Result for The Control and Experimental groups}

The statistic description and analysis for total scores result were also calculated to validate the data of both cognitive and practical test. The total scores were taken from the cognitive score plus the practical score divided by two. In other words, these total scores are average scores of both cognitive and practical scores. The total score descriptive data analysis is presented in table 7 .

These total data scores were also analyzed using Kolmogorov-Smirnov and Shapiro-Wilk to check the normality data and Levene Statistic to check the variances' homogeneity. Both results are presented in Table 8 and Table 9.

Based on Table 8, the significance level for both control and experimental groups fall higher than 0.05 . Thus, both groups' data are considered normally distributed. Further, the result of homogeneity of variances using Levene Statistic stated that both groups are homogeny. It can be seen in table 9 that the significance level is 0.944 . It is higher than 0.05 .

All the requirements for testing the sample using parametric analysis of independent sample $t$-test were fulfilled since both groups were normally distributed and had significant homogeneity of variances. Therefore, parametric analysis was applied to find the effectiveness of the implementation of RADEC in LMS to teach Tennis without field practicing.

\section{The Cognitive Post-Test Result for The Control and Experimental groups}

This research was employed null-hypothesis, where it is stated that there is no significant difference between the control group and the experimental group after the different treatments were applied. To test the hypothesis, an independent sample t-test was used for the scores of cognitive, practical, and total test results. The result can be seen in Table 10.

Based on table 10, the significance level falls in 0.103 . At this point, 0.103 is higher than $\alpha(0.103>0.05)$. Since the sig. (2-tailed) is higher than 0.05 . The null hypothesis is accepted. It can be interpreted that based on the statistical analysis, there is no difference between the control group and the experimental group in terms of cognitive score results. In other words, teaching Tennis in LMS using RADEC is proven as efficient as teaching Tennis using the typical approach for cognitive.

Table 8. Test of Normality Data for Total Pre-test Score

\begin{tabular}{lcccccccc}
\hline \multirow{2}{*}{} & \multirow{2}{*}{ Group } & \multicolumn{3}{c}{ Kolmogorov-Smirnov $^{\mathrm{a}}$} & \multicolumn{3}{c}{ Shapiro-Wilk } \\
\cline { 3 - 8 } & & Statistic & $\mathrm{df}$ & Sig. & Statistic & $\mathrm{df}$ & Sig. \\
\hline \multirow{2}{*}{ Total Pre-test Result } & Control & .102 & 30 & $.200^{*}$ & .969 & 30 & .508 \\
\cline { 2 - 8 } & Experiment & .144 & 33 & .080 & .970 & 33 & .468 \\
\hline
\end{tabular}

*. This is a lower bound of the true significance.

a. Lilliefors Significance Correction

Table 9. Test of Homogeneity of Variance for Total Pre-test Scores

\begin{tabular}{cccc}
\hline & Total Pre-test Result & & \\
\hline Levene Statistic & $\mathrm{df1}$ & $\mathrm{df2}$ & Sig. \\
\hline .005 & 1 & 61 & .944 \\
\hline
\end{tabular}

Table 10. Group Statistic and Result of Independent sample t-test for Cognitive Achievement.

\begin{tabular}{|c|c|c|c|c|c|c|c|c|c|c|}
\hline \multicolumn{11}{|c|}{ Group Statistics } \\
\hline & & \multicolumn{2}{|c|}{ Group } & $\mathrm{N}$ & \multicolumn{2}{|c|}{ Mean } & \multicolumn{2}{|c|}{ Std. Deviation } & \multicolumn{2}{|c|}{ Std. Error Mean } \\
\hline \multirow{2}{*}{\multicolumn{2}{|c|}{$\begin{array}{c}\text { Cognitive Post-test } \\
\text { Result }\end{array}$}} & \multicolumn{2}{|c|}{ Control } & 30 & \multicolumn{2}{|c|}{79.0000} & \multicolumn{2}{|c|}{8.30039} & \multicolumn{2}{|c|}{1.51544} \\
\hline & & \multicolumn{2}{|c|}{ Experiment } & 33 & \multicolumn{2}{|c|}{75.8182} & \multicolumn{2}{|c|}{6.93476} & \multicolumn{2}{|c|}{1.20719} \\
\hline \multicolumn{11}{|c|}{ Independent Samples Test } \\
\hline & & \multirow{2}{*}{\multicolumn{5}{|c|}{$\begin{array}{c}\text { Levene's Test for } \\
\text { Equality of } \\
\text { Variances }\end{array}$}} & \multirow{2}{*}{\multicolumn{3}{|c|}{ t-test for Equality of Means }} & \\
\hline & & & & & & & & & & \\
\hline & & \multirow[t]{2}{*}{$\mathrm{F}$} & \multirow[t]{2}{*}{ Sig. } & \multirow[t]{2}{*}{$\mathrm{t}$} & \multirow[t]{2}{*}{ df } & \multirow{2}{*}{$\begin{array}{c}\text { Sig. } \\
\text { (2-tailed) }\end{array}$} & \multirow{2}{*}{$\begin{array}{c}\text { Mean } \\
\text { Difference }\end{array}$} & \multirow{2}{*}{$\begin{array}{l}\text { Std. Error } \\
\text { Difference }\end{array}$} & \multicolumn{2}{|c|}{$\begin{array}{l}\text { 95\% Confidence Interval of the } \\
\text { Difference }\end{array}$} \\
\hline & & & & & & & & & Lower & Upper \\
\hline \multirow{2}{*}{$\begin{array}{c}\text { Cognitive } \\
\text { Post-test } \\
\text { Result }\end{array}$} & $\begin{array}{c}\text { Equal } \\
\text { variances } \\
\text { assumed }\end{array}$ & .645 & .425 & 1.656 & 61 & .103 & 3.18182 & 1.92088 & -.65921 & 7.02285 \\
\hline & $\begin{array}{c}\text { Equal } \\
\text { variances not } \\
\text { assumed }\end{array}$ & & & 1.642 & 56.767 & .106 & 3.18182 & 1.93749 & -.69828 & 7.06191 \\
\hline
\end{tabular}


Reference [16] has proven that learners are more interested in viewing lecture slides or videos than shared assignments and posted messages in LMS. Further, Reading as the first step of RADEC allows the learners to view and read lecture slides and videos given in LMS. This activity replaces lecturing in conventional teaching. Moreover, by viewing LMS material, learners get their opportunity to choose, repeat, and re-read the material given. Learners can freely decide which part of the material they want to learn first and last.

Moreover, this type of LMS learning is like a self-regulated process. Thus, motivation is essential for learners to access the material and process them [17]. During this COVID-19 pandemic, learners have their own intrinsic and high extrinsic motivation to learn using LMS. The automatic learners' metacognitive is activated to reach curriculum achievement. Whether the lecture like it or not, learners' motivation, participation, and learning motivation are the lecturer's final score [18].

The second step of RADEC is Answering. After accessing the given material, learners get opportunities to ask questions and answer questions presented by lecturers or the other learners. LMS allows learners to post any questions related to the material in LMS's wall. This type of communication provides interaction between learners in the same class. Learners prefer spending time to have online discussion compared to reading material [19]. Not only Answering, in this part, Explaining for the specific information related to the material given is also engaged. Learners are given their time and effort to explain their LMS understanding, most likely in written form. This interaction can automatically build from the other learners' questions on the LMS wall, or lecturers may trigger the explanation by asking open discussion. This activity is similar to the discussion process in typical classroom activities.

To this point, the cognitive achievement of teaching Tennis in the typical classroom and LMS using RADEC (in this part is Reading, Answering, and Explaining) has similar attributes. It explains the accepted null-hypothesis for learners' cognitive achievement that there are no significant differences between learners' cognitive achievement in the typical classroom and LMS using RADEC.

\section{The Practical Post-Test Result for The Control and Experimental groups}

One obstacle in teaching sport using LMS is in practice sessions. Learners have to have their motivation, understanding, and personal judgment to the movement they act according to the material given. Learners need to have comprehensive information about the material. Using RADEC, a thorough understanding can be achieved, as explained previously, covered by Reading, Answering, and Explaining. Further, the implementation of the understanding is covered in Demonstrating and Creating.

The effectiveness comparison between the control and experimental group for practical achievement in Tennis was tested. Using the null-hypothesis, where there is no significant difference between the achievement result for practical tennis achievement in the control and experimental group, the independent sample t-test was performed. The result can be seen in table 11 .

Table 11. Group Statistic and Result of Independent sample t-test for Practical Achievement.

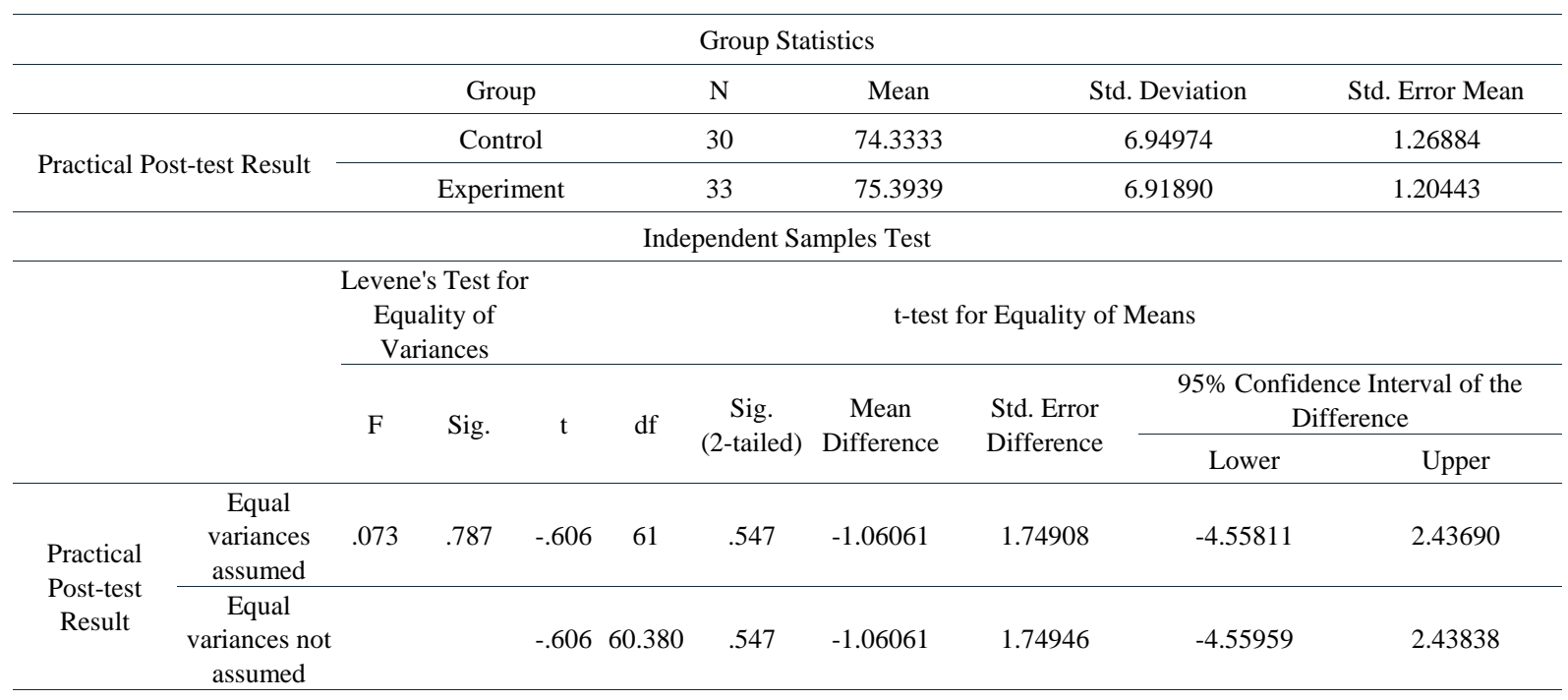


Table 11 shows that the significance level using independent sample t-test falls in 0.547. This result is higher than $\alpha \quad(0.547>0.05)$. It means that the null-hypothesis is accepted. Therefore, this acceptance means no significant differences between control and experimental groups in terms of practical achievement.

This result is noticeably surprising since learners only practice the tennis movements on their own and video supporting material in LMS. However, the achievement performance was limited to six basic tennis movements: serve, forehand groundstroke, backhand groundstroke, forehand volley, backhand volley, and overhead smash. The real matches were excluded. Those six basic tennis movements were performed partially.

Researchers believe that the best learning tennis is by doing field practicing, where learners can interact directly with the coaches, tennis court, rackets, and tennis ball. Therefore, most of them research the perfect fit method to be applied during field practicing. Begin with Neuman and Singer [20] that created programmed learning methods, until the recent research by $\mathrm{Yu}$ et al. [21] with their video-based reflective learning using motion tracking sensors, teaching Tennis is best applied with the practice directly.

However, this method is not the only effective way to learn Tennis. This method has been researched ages ago by Van Wieringen et al. [22]. They discussed how intermediate players learned the tennis service using video-feedbacks. The result shows a noticeable improvement in achieving the score and form of service [22]. It develops to augment feedback on tennis skill acquisition [23] and applying motion-tracking sensors in a smartphone video application [21].

Further, it can be stated that from time to time, learning tennis with and without field practicing was proven useful to some extends. Thus, the result of implementing RADEC in LMS as one of the alternatives to learn Tennis without filed practicing is possible. Moreover, RADEC offers additional ways to guide tennis coaches' lecturers by the other two steps Demonstrating and Creating.

In the Demonstrating step, learners are asked to understand from the three previous steps (Reading, Answering, Explaining) by recording and uploading it to LMS. Learners get feedback for their uploaded video not only by lecturers but also from their classmates. Different feedback complexity on learning affects learner performances differently, yet it maximizes learning [24]. The eagerness of learners to follow the feedback given by lecturers and their classmates can be seen in performing the test. The choice to accept the feedbacks and improve the movement is on the learners' decision.

In conventional tennis learning, feedback is given directly by lecturers or classmates. It allows learners to ask direct questions for every feedback given. They can ask for another feedback right after implementing the given feedback. It is one advantage that learners in LMS cannot have. However, by having video in the Reading step, learners can pause, rewind, and forward the video to their weak point, not to mention they can also do a slow-motion for the video. Learners can compare the feedback to the video uploaded by lecturers or coaches.

This multimedia platform has been researched related to learning Tennis. HTML5 video elements, WebVTT (Web Video Text Tracks), and MySQL were used to learn table tennis [25]. The result is effective as an adjunct to standard coaching techniques. Meanwhile, this research used the standard form of LMS applied with RADEC. Based on the statistic result in table 11., this method, to some extends, can be one of the alternatives to teaching Tennis without field practicing.

\section{The Total Post-Test Result for The Control and Experimental groups}

For most teaching and learning procedures, especially in physical education, the achievement criteria are based on learners' two scores (cognitive and practice). Physical Education pre-service teachers are prepared to master both pedagogical knowledge and motoric skills [26]. Therefore, successful physical education learning is depended on those two skills that learners should master. The way the lectures or teachers combine those two skills to achieve the curriculum goal is turned on the lecturers or teachers themselves. It can be weighted based on the complexity of the test. In this research, the weighting percentages for both cognitive and motoric skills are $50 \%$. So, the total scores are taken by the average of both cognitive and practical test scores.

To validate the partial scores of cognitive and practical, the total scores of both control and experimental groups were also calculated using an independent sample t-test. The result can be seen in table 12 . 
Table 12. Group Statistic and Result of Independent sample t-test for Total Achievement.

\begin{tabular}{|c|c|c|c|c|c|c|c|c|c|c|}
\hline \multicolumn{11}{|c|}{ Group Statistics } \\
\hline & & & \multicolumn{2}{|c|}{ Group } & \multicolumn{2}{|r|}{$\mathrm{N}$} & \multicolumn{2}{|c|}{ Mean } & Std. Deviation & Std. Error Mean \\
\hline \multirow{2}{*}{\multicolumn{2}{|c|}{ Total Post-test Result }} & & \multicolumn{2}{|c|}{ Control } & & 30 & \multicolumn{2}{|c|}{76.6667} & 6.98438 & 1.27517 \\
\hline & & & \multicolumn{2}{|c|}{ Experiment } & & 33 & \multicolumn{2}{|c|}{75.6061} & 1258 & 1.16851 \\
\hline \multicolumn{11}{|c|}{ Independent Samples Test } \\
\hline & & \multicolumn{3}{|c|}{$\begin{array}{c}\text { Levene's Test for } \\
\text { Equality of } \\
\text { Variances }\end{array}$} & \multicolumn{6}{|c|}{ t-test for Equality of Means } \\
\hline & & \multirow[t]{2}{*}{$\mathrm{F}$} & \multirow[t]{2}{*}{ Sig. } & \multirow[t]{2}{*}{$\mathrm{t}$} & \multirow[t]{2}{*}{$\mathrm{df}$} & \multirow{2}{*}{$\begin{array}{c}\text { Sig. } \\
\text { (2-tailed) }\end{array}$} & \multirow{2}{*}{$\begin{array}{c}\text { Mean } \\
\text { Difference }\end{array}$} & \multirow{2}{*}{$\begin{array}{l}\text { Std. Error } \\
\text { Difference }\end{array}$} & \multicolumn{2}{|c|}{$\begin{array}{l}\text { 95\% Confidence Interval of the } \\
\text { Difference }\end{array}$} \\
\hline & & & & & & & & & Lower & Upper \\
\hline \multirow{2}{*}{$\begin{array}{l}\text { Total Post-test } \\
\text { Result }\end{array}$} & $\begin{array}{c}\text { Equal } \\
\text { variances } \\
\text { assumed }\end{array}$ & .068 & .795 & .614 & 61 & .541 & 1.06061 & 1.72627 & -2.39128 & 4.51249 \\
\hline & $\begin{array}{c}\text { Equal } \\
\text { variances not } \\
\text { assumed }\end{array}$ & & & .613 & 59.885 & .542 & 1.06061 & 1.72959 & -2.39922 & 4.52043 \\
\hline
\end{tabular}

As expected, the independent sample t-test for the total score significance falls in $0.541>0.05$. Thus, the null-hypothesis for total scores is also accepted. It can be interpreted that there is no significant difference between the control and experimental groups. It validates the partial result of cognitive and practical achievement previously.

However, the average score post-test result of cognitive scores in the control group is 79 , and in the experimental group is 75.93. Meanwhile, the average practical post-test score in the control group is 74.33. It is slightly lower than the average practical post-test score in the experimental group, 75.6. This circumstance affects the total score for both groups. The control group average total post-test score is slightly higher than in the experimental group (76.67>75.61). Although it can be said that conventional tennis teaching achieves better compared to the RADEC in LMS, the difference is not significant, as in table 12.

\section{Conclusions}

The various learning obstacles force practitioners and researches to develop the most proper and fittest learning methodology. Creating innovation to hinder the challenges and increase the learners' achievement toward one material delivered is inevitable. As this industry 4.0 era, computers and other technologies such as CALL or Re-CALL help teachers and learners learn even better[1].

Therefore, this paper offers one alternative learning tennis to conventional tennis coaching during this horrific pandemic, which prevents direct interaction between lecturers and learners. The method allows learners to achieve curriculum goals of tennis lessons in physical education major in LMS without field practicing. After doing a set of independent sample t-test for cognitive and practical achievement, all null-hypothesis is accepted. It can be interpreted that there are no significant differences in learning tennis between the typical way and leaning using RADEC in LMS.

However, physical education's main objective related to participants' physical fitness and skill building in the experiment group was not fully observed. This research focuses only on the result of the test given to both control and experiment groups.

This research's most significant contribution is that RADEC in LMS can be one alternative method to be applied by lecturers or coaches. However, this method's effectiveness is limited to six basic movements of Tennis: serve, forehand groundstroke, backhand groundstroke, forehand volley, backhand volley, and overhead smash. All those six movements were performed and tested partially. Thus, there is still a lot of research space to analyze Tennis's other skills, especially when the skills are integrated from one to another, including during matches. So, more researches and studies are still needed.

\section{Acknowledgment}

This research is partially supported by Pre-Service Elementary School Teacher Program for Physical Education, Universitas Pendidikan Indonesia, Indonesia.

\section{REFERENCES}

[1] Rahman AA, Angraeni A. Empowering Learners with Role-Playing Game for Vocabulary Mastery. International Journal of Learning, Teaching and Educational Research. 2020;19(1).

[2] Ellsworth E. Places of Learning: Media, Architecture, Pedagogy. Routledge; 2005. 201 p.

[3] Kristanto A, Mustaji, Mariono A. The Development of Instructional Materials E-Learning Based on Blended 
Learning. International Education Studies. 2017;10(7):10-7.

[4] Panigrahi R, Srivastava PR, Sharma D. Online learning: Adoption, continuance, and learning outcome-A review of literature. International Journal of Information Management. 2018 December 1;43:1-14.

[5] Lancker WV, Parolin Z. COVID-19, school closures, and child poverty: a social crisis in the making. The Lancet Public Health. 2020 May 1;5(5):e243-4.

[6] Services D of H\& H. Tennis - health benefits [Internet]. Department of Health \& Human Services; [cited 2020 July 15]. Available from:https://www.betterhealth.vic.gov.au:44 3/health/healthyliving/tennis-health-benefits

[7] Crespo M, Reid MM, Miley D. Tennis: Applied Examples of a Game-based Teaching Approach. Strategies. 2004 March $1 ; 17(4): 27-30$

[8] Pill S, Hewitt M. Tennis Coaching: Applying the Game Sense Approach. Strategies. 2017 March 4;30(2):10-6.

[9] Jia W. Inquiry Teaching Method and Its Application in College Tennis Teaching. In 2019 [cited 2020 Jul 15]. Available from: https://webofproceedings.org/proceedings_ series/article/artId/11361.html

[10] Mowling CM, Fittipaldi-Wert J, Favoretto L. Soundball: Teaching Tennis to Students with Visual Impairments. Strategies. 2017 July 4;30(4):3-10.

[11] Glenberg AM. How Reading Comprehension is Embodied and Why that Matters. International Electronic Journal of Elementary Education. 2011;4(1):5-18.

[12] Cotos E, Huffman S, Link S. A move/step model for methods sections: Demonstrating Rigour and Credibility. English for Specific Purposes. 2017 April 1;46:90-106.

[13] Fraenkel JR, Wallen NE, Hyun HH. How to design and evaluate research in education. Vol. 7. McGraw-Hill New York; 1993.

[14] Mitchell ML, Jolley JM. Research Design Explained. Cengage Learning; 2012. 756 p.

[15] Campbell DT, Stanley JC. Experimental and Quasi-Experimental Designs for Research. Ravenio Books; 2015. $92 \mathrm{p}$.
[16] Li L-Y, Tsai C-C. Accessing online learning material: Quantitative behavior patterns and their effects on motivation and learning performance. Computers \& Education. 2017 Nov 1;114:286-97.

[17] Cho M-H, Kim BJ. Students' self-regulation for interaction with others in online learning environments. The Internet and Higher Education. 2013 April 1;17:69-75.

[18] Broadbent J, Poon WL. Self-regulated learning strategies \& academic achievement in online higher education learning environments: A systematic review. The Internet and Higher Education. 2015 October 1;27:1-13.

[19] Fung* YY. Collaborative online learning: Interaction patterns and limiting factors. Open Learning: The Journal of Open, Distance and e-Learning. 2004;19(2):135-49.

[20] Neuman MC, Singer RN. A comparison of traditional versus programed methods of learning Tennis. Research Quarterly American Association for Health, Physical Education and Recreation. 1968;39(4):1044-8.

[21] Yu C-H, Wu C-C, Wang J-S, Chen H-Y, Lin Y-T. Learning Tennis through Video-based Reflective Learning by Using Motion-Tracking Sensors. Journal of Educational Technology \& Society. 2020;23(1):64-77.

[22] Van Wieringen P, Emmen H, Bootsma R, Hoogesteger M, Whiting $\mathrm{H}$. The effect of video-feedback on the learning of the tennis service by intermediate players. Journal of Sports Sciences. 1989;7(2):153-62.

[23] Hebert EP, Landin D. Effects of a learning model and augmented feedback on tennis skill acquisition. Research quarterly for exercise and sport. 1994;65(3):250-7.

[24] Wang Z, Gong S-Y, Xu S, Hu X-E. Elaborated feedback and learning: Examining cognitive and motivational influences. Computers \& Education. 2019;136:130-40.

[25] Zou J, Liu K, Han L. The impact of a rich media platform to table tennis learners' performance and participation motivation. Interactive Learning Environments. 2019;1-13.

[26] Legrain P, Escalié G, Lafont L, Chaliès S. Cooperative learning: a relevant instructional model for physical education pre-service teacher training? Physical Education and Sport Pedagogy. 2019;24(1):73-86. 